\title{
Mobile produce market influences access to fruits and vegetables in an urban environment
}

\author{
Bi-sek Hsiao', Lindiwe Sibeko' ${ }^{1}$, Kathy Wicks ${ }^{2}$ and Lisa M Troy ${ }^{1, *}$ \\ 'Department of Nutrition, School of Public Health and Health Sciences, 206 Chenoweth Lab, University of \\ Massachusetts, Amherst, MA 01003, USA: ${ }^{2}$ Partners for a Healthier Community, Springfield, MA, USA
}

Submitted 20 March 2017: Final revision received 11 September 2017: Accepted 16 November 2017: First published online 10 January 2018

\begin{abstract}
Objective: To assess the influence of a mobile produce market (MPM) on fruit and vegetable access.

Design: Novel application of a structured assessment (five dimensions of access framework) to examine fruit and vegetable access through self-administered surveys on shopping behaviours, and perceptions and experiences of shopping at the MPM.

Setting: Low-income neighbourhoods with limited access to fruits and vegetables. Subjects: Older ( $\geq 60$ years) and younger (18-59.9 years) shoppers.

Results: Participants were more likely to be women and non-White, one-third lived alone and nearly half were older adults. Compared with younger, older participants had different shopping behaviours: tended to purchase food for one person $(P<0.001)$, be long-term shoppers $(P=0.002)$ and use electronic benefit transfer (EBT) cards $(P=0 \cdot 012)$. Older adults were more likely to like the market location $(P=0.03)$, while younger adults were more likely to want changes in location $(P=0.04)$, more activities $(P=0.04)$, taste sampling $(P=0.05)$ and nutritional counselling $(P=0 \cdot 01)$. The MPM captured all dimensions of access: availability, indicated by satisfaction with the produce variety for nearly one-third of all participants; accessibility, indicated by participants travelling $<1$ mile $(<1.6$ $\mathrm{km} ; 72.2 \%)$ and appreciation of location ( $72.7 \%)$; affordability, indicated by satisfaction with price ( $47.6 \%$ ); acceptability, indicated by appreciation of produce quality (46.2\%); and accommodation, indicated by satisfaction with safety of location (30.1\%) and high EBT use among older adults (41.8\%).

Conclusions: MPM may influence fruit and vegetable access in low-income urban neighbourhoods by facilitating the five dimensions of access and may especially benefit older adults and individuals living alone.
\end{abstract}

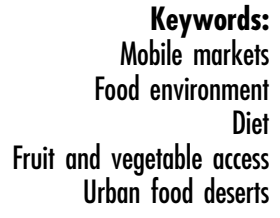

Keywords: Mobile markets Diet Urban food deserts
Fruits and vegetables are important for the prevention and management of chronic diseases ${ }^{(1,2)}$, yet US national data show that in 2013 , fewer than $18 \%$ of adults consumed the recommended amount of fruits and fewer than 14\% consumed the recommended amount of vegetables ${ }^{(3)}$. Food environment research indicates that availability of fruits and vegetables in neighbourhood stores and living in close proximity to a supermarket are associated with increased fruit and vegetable consumption ${ }^{(4,5)}$, while fastfood availability is associated with decreased consumption $^{(6)}$. Research across the USA shows that low-income and minority neighbourhoods have disproportionately fewer supermarkets and healthful food outlets, while surrounded by a larger presence of fast-food restaurants and consequentially greater availability of energy-dense foods ${ }^{(7,8)}$. Deficiencies of healthful food environments among low-income and minority populations contribute to their susceptibility to poor health and health disparities ${ }^{(9)}$.

Studies of the food environment-diet relationship most commonly use the availability of healthful food as an indicator of access; either through macro-level measures such as supermarket presence or micro-level measures such as in-store food audits ${ }^{(10)}$. However, many nuances related to how people access healthful foods are often missed, such as perceptions of access, the temporal availability of food outlets (e.g. store hours) ${ }^{(11)}$, and the pricing, placement and promotion of foods ${ }^{(12)}$. The five dimensions of access, first proposed as a framework for measuring access to health care ${ }^{(13)}$, has recently been proposed to guide more comprehensive measures of access to healthful foods ${ }^{(10)}$. Previous studies have applied this framework to examine food access based on 
perceptions and interactions with the food environment $^{(14,15)}$, but to our knowledge, none have applied this framework to evaluate a food environment intervention. We apply the five dimensions - availability, accessibility, affordability, acceptability and accommodation - to better understand the complexity of access to fruits and vegetables in the context of a food environment intervention, a mobile produce market (MPM).

MPM, which are portable fruit and vegetable markets, contribute an important yet often overlooked source of food in food environments nationally and internationally. For example, mobile food carts in the colonias along the South Texas border with Mexico ${ }^{(16,17)}$, fruteros or fruit vendors in Los Angeles ${ }^{(18)}$ and Green Carts in the Bronx $^{(19)}$ provide an alternative market for purchasing fruits and vegetables to supermarkets, which may be less accessible because of travel distance ${ }^{(9)}$, and local convenience stores, which may have few options for fruits and vegetables ${ }^{(20)}$. In developing countries, informal markets and mobile vendors serve as a primary source of fruits and vegetables among vulnerable populations in some urban and rural areas. One study found that $95 \%$ of low-income households in Hanoi, Vietnam purchased fruits and vegetables several times per week from informal stationary markets and $32 \%$ from mobile vendors, citing as advantages proximity to home, low prices and possibilities to buy on credit ${ }^{(21)}$. However, it should be noted that the percentage of purchases of fruits and vegetables varies greatly in different areas. For example, fruit as a percentage of total purchases from mobile vendors was $58.6 \%$ in South Africa ${ }^{(22)}, 18.5 \%$ in Haiti ${ }^{(23)}$ and $4.4 \%$ in Burkina Faso $^{(24)}$, and vendors sold a mix of food types with many vendors predominantly selling prepared foods ${ }^{(25)}$.

In the USA and UK, MPM have received attention in recent years as a strategy to increase access to and consumption of fruits and vegetables, particularly among populations with greater health risk ${ }^{(26-31)}$. A range of target populations have been described in MPM intervention studies, including elementary-school students ${ }^{(29)}$, older $\operatorname{adults}^{(26,28)}$, low-income families ${ }^{(28)}$, predominantly Hispanic and Black neighbourhoods ${ }^{(27)}$, areas of low fruit and vegetable consumption $^{(19,28,32,33)}$, areas of low produce availability $^{(19,32,33)}$ and areas with high rates of heart disease, stroke and diabetes ${ }^{(28)}$. Older adults are an important target population for MPM because older adults are at increased vulnerability to the cumulative health impediments of chronic diseases ${ }^{(34)}$ and face additional barriers to obtaining fruits and vegetables, such as being on a fixed income and having physical limitations that may impede their ability to reach and shop at distant markets ${ }^{(35,36)}$.

The purpose of the present study was to apply the five dimensions of access framework to examine MPM influences on fruit and vegetable access within an urban, low-income population and to examine differences in perceptions of access between older ( $\geq 60$ years) and younger (18-59.9 years) adults. We compared older and younger adults because older adults often have increased vulnerabilities such as chronic disease management and less mobility that increase the challenges to access fruits and vegetables, and may have different shopping behaviours, perceptions and experiences related to MPM. To our knowledge, the present study is the first to apply a structured assessment, the five dimensions of access framework, to examine an intervention aiming to increase fruit and vegetable access.

\section{Methods}

\section{Setting}

Springfield is the third largest city in Massachusetts, USA, and in 2015 had an estimated population of $154341^{(37)}$. The latest statistics on race/ethnicity from 2015 showed that the Springfield population has a much higher population of colour compared with Massachusetts overall: Black/African American (21.7 v. 6.9\%), Hispanic/Latino (38.0 v. 9.3\%), Asian (2.2 v. 5.6\%) and non-Hispanic White $(35.4 v \cdot 75.7 \%)^{(38)}$. Older adults $\geq 60$ years represented $15.9 \%$ of Springfield's population in $2015^{(39)}$.

The current study examined eight Springfield neighbourhoods that were part of an MPM intervention. The largest racial/ethnic group in all but one of the eight neighbourhoods was Hispanics $(35 \cdot 1-80 \cdot 8 \%$, one neighbourhood at $14.0 \%$ ); other ethnic/racial groups in the eight neighbourhoods were as follows: non-Hispanic Whites $(6 \cdot 8-32 \cdot 2 \%$, one neighbourhood at $62.0 \%)$, Blacks $(11 \cdot 5-33 \cdot 1 \%)$ and Asians $(0 \cdot 1-4 \cdot 8 \%)^{(38)}$. Older adults aged $\geq 60$ years ranged from $9 \cdot 5$ to $20 \cdot 1 \%$, and younger adults aged 18-59.9 years ranged from 52.9 to $61.2 \%$, of the eight neighbourhoods' populations ${ }^{(39)}$. Poverty rates showed that approximately half of the population lived under the poverty line (range 48.9$63.6 \%$ ) in four neighbourhoods and poverty rates ranged from $15 \cdot 1$ to $29.6 \%$ in the other four neighbourhoods ${ }^{(40)}$.

Food access maps showed more than half of Springfield, MA census tracts as food deserts, defined as having a substantial share (i.e. $\geq 500$ residents or $33 \%$ of residents in census tracts) of low-income residents living $>0.5$ miles $(>0.8 \mathrm{~km})$ away from a supermarket ${ }^{(41)}$. Portions of all eight neighbourhoods in the MPM intervention were classified as food deserts, and five neighbourhoods were entirely food deserts ${ }^{(41)}$.

\section{Go Fresh mobile produce market}

The Go Fresh MPM in Springfield, MA aims to improve access to locally grown fruits and vegetables and is a notfor-profit multi-organizational collaboration that includes city departments, a public health institute, three farms, a community action organization and a non-profit community loan organization. Launched in 2011, Go Fresh sells locally grown fresh fruits and vegetables (average of twenty varieties per week), such as berries, apples, 
tomatoes, leafy greens and squash, from June to October in neighbourhoods with limited access to fruits and vegetables. The project has consistently provided 50\% discount for all Supplemental Nutrition Assistance Program (SNAP) participants to assist low-income shoppers to purchase produce. In 2014, Go Fresh operated three days per week and was scheduled for weekly stops, each lasting 1 to $1 \frac{1}{2} \mathrm{~h}$, at twelve locations in eight of Springfield's seventeen neighbourhoods. Go Fresh locations included subsidized housing complexes, senior centres and other sites of congregation. For purposes of the present study, data were collected at all twelve Go Fresh locations operated during the 2014 season.

\section{Study participants and design}

Cross-sectional survey data were collected from a convenience sample of Go Fresh shoppers, recruited during the last two weeks of the Go Fresh 2014 season, from 22 to 31 October. All shoppers, estimated to be 180, were asked to complete the questionnaire and 147 shoppers agreed to participate. Questionnaires missing data on age or sex were excluded ( $n$ 4) leaving a final sample of 143 participants.

\section{Study questionnaire}

A twenty-item questionnaire was self-administered and included information on demographics, shopping behaviours, and perceptions and experiences about Go Fresh. Demographics included age (12-17, 18-24, 25-29, 30-39, 40-49, 50-59, 60-69, >70 years), sex (male/female), race/ ethnicity (Hispanic, White, Black, Asian, American Indian, Native Hawaiian or Pacific Islander, other - write in), neighbourhood residence, and living alone or with others. Shopping behaviours included amount of money spent at Go Fresh on the day of the survey (\$US: 0-5, 5-10, 11-20, 21-30, 31-40, 41-50, 51-75, >75), shopping frequency at Go Fresh (weekly, twice/month, once/month, once or twice, first time), primary shopper for the household (yes/ no), the number of people purchasing food for $(1,2-3$, $4-5,>5)$, number of Go Fresh locations shopped this year ( $1,>1$ location), duration of shopping at Go Fresh (first year, second year, started 2-3 years ago) and plans to shop at Go Fresh next year (yes, no, don't know). There were two open-ended questions: 'Are there any vegetables or fruits missing from the Go Fresh mobile market that you wish were available?' and 'Please share any other comments you have'. The questionnaire was offered in three languages (English, Spanish and Vietnamese) to reflect the most common races/ethnicities of shoppers.

\section{Five dimensions of access}

We adapted the five dimensions of access defined by Capsi and colleagues ${ }^{(10)}$. 'Availability' refers to the supply of food, including amount, type and variety, and the presence of certain store types; 'accessibility' refers to the location of the food supply and the convenience of reaching it; 'affordability' refers to prices of food or perceptions of cost; 'acceptability' refers to the quality of food; and 'accommodation' refers to the extent that food sources adapt to consumer needs, with attention to store hours and types of payment ${ }^{(10)}$. For the purposes of our study, the five dimensions were assessed by the following: availability by perceptions of produce variety; accessibility by perceptions of location and distance travelled to the MPM; affordability by perceptions of produce price; acceptability by perceptions of produce quality; and accommodation by perceptions of market hours, safety of market location, community-led activities at the market and use of electronic benefit transfer (EBT) cards at the market.

We used indicators of perceived access because previous research shows that perceived measures are more strongly related to dietary behaviours than objective measures $^{(42,43)}$ and are instrumental to explain nuances influencing individuals' self-efficacy to intake of healthful foods ${ }^{(44)}$. In the current study, two main questions captured measures of perceived access: (i) 'What do you like about the Go Fresh mobile market?' and (ii) 'What would you like to see changed about the Go Fresh mobile market for next year?', with response options to capture perceptions of the following: produce variety (availability); market location (accessibility), produce cost/pricing (affordability); 'produce is locally grown' as a proxy for quality $^{(45)}$ (acceptability); hours of operation, safety of location and activities led by community organizations, such as food demonstrations and visit by a nutritionist from the Special Supplemental Nutrition Program for Women, Infants, and Children (accommodation). Participants were asked to 'circle all that apply' and there was an 'other' open-ended write-in response option. Two questions captured more objective measures of access. For accessibility, 'How far did you travel to get to the Go Fresh mobile market today?' (<1, 1-5, 6-10, 11-25, 26-50 miles ( $<1 \cdot 6$, $1 \cdot 6-8 \cdot 0,9 \cdot 6-16 \cdot 0,17 \cdot 7-40 \cdot 2,41 \cdot 8-80 \cdot 5 \mathrm{~km})$ ) captured an objective measure of distance travelled. For accommodation, 'Have you ever used an EBT card to purchase your produce at the Go Fresh mobile market?' (yes/no) captured an objective measure of payment type. In addition, write-in responses to 'Please share any other comments you have' were categorized into one of the five dimensions of access.

\section{Statistical analysis}

Frequencies and percentages were calculated to describe participant characteristics and shopping behaviours. Age was collapsed into two categories, older adults ( $\geq 60$ years) and younger adults (18-59.9 years); younger age categories had relatively few participants per category (18-24 years, $n 7$; 25-29 years, $n 11$; 30-39 years, $n$ 19; 40-49 years, $n 18$; 50-59 years, $n$ 27) compared with older adults ( $n$ 61). A $\chi^{2}$ analysis was used to identify significant differences in participant characteristics and shopping behaviours between older and younger participants. 
Separate logistic regression models were used to examine four shopping behaviours: EBT use (yes/no), amount of money spent at Go Fresh ( $\leq$ \$US 10/> \$US 10), shopping frequency at Go Fresh (<weekly/weekly) and distance travelled to Go Fresh $(<1$ mile $/ \geq 1$ mile $(<1.6 \mathrm{~km} /$ $\geq 1.6 \mathrm{~km})$ ), with the following variables in the models: age (18-59.9 years/ $\geq 60$ years), race/ethnicity (non-White/ White), sex (male/female) and living situation (living alone/ living with others); EBT use (yes/no) was added to models examining money spent, shopping frequency and distance travelled. Each logistic regression model included only participants with complete data for that model.

Frequencies and percentages were used to capture perceptions and experiences of the MPM. Each dimension of the five dimensions of access in influencing fruit and vegetable access was assessed through the absolute percentages of responses. For each dimension, a $\chi^{2}$ analysis was used to identify significant differences between older and younger participants.

Statistical significance was set at $P<0.05$. Statistical analyses were conducted using the statistical software package Stata release 14 .

\section{Results}

Participant characteristics are provided in Table 1. Participants were more likely to be women (69.9\%) and were nearly evenly distributed between older (42.7\%) and younger $(57.3 \%)$ age categories. Older participants were Black (32.1\%), White (25.0\%), Hispanics (21.4\%) and Asian (19.6\%), while Hispanics represented a larger proportion of younger participants $(46 \cdot 2 \% ; P=0.02)$.

Participant shopping behaviours are provided in Table 2 . Most participants were their household's primary food purchaser (86.6\%) and reported purchasing food for two or three people (58.5\%). Nearly half (44.2\%) of the participants shopped at Go Fresh weekly and most (84.2\%) shopped only at one Go Fresh location. For the majority of participants, 2014 was the first year of shopping at Go Fresh (72.1\%), and nearly all participants (92.9\%) planned to shop at Go Fresh the following year. The median range of money spent was \$US 5-10, with $36.6 \%$ of participants spending less than \$US 5 and $25.4 \%$ spending more than \$US 10 at Go Fresh on the day of the survey. The most common means that participants found out about Go Fresh was through a community organization (41.3\%), followed by friends (28.0\%), flyers/ postcards (19.6\%) and passing by the market (14.7\%).

Compared with younger participants, older participants were more likely to live alone $(P<0.001$; Table 1$)$, purchase food for one person $(P<0.001)$, be long-term shoppers (for 2-3 years; $P=0.002)$ and use EBT $(P=0 \cdot 01$; Table 2). Older participants shopped more regularly at Go Fresh - weekly and once/twice monthly - compared with younger adults, one-third of whom shopped there only once or twice in the season $(P=0.09$; Table 2$)$.

EBT use was associated with living alone $(\mathrm{OR}=2 \cdot 5$, $P=0 \cdot 03)$ and being older (OR=2.1, $P=0 \cdot 09)$. Weekly shopping at Go Fresh was associated with living alone $(\mathrm{OR}=2 \cdot 5, P=0 \cdot 03)$. Travelling $<1$ mile $(<1.6 \mathrm{~km})$ to Go Fresh was associated with living alone $(\mathrm{OR}=2 \cdot 6, P=0 \cdot 02)$ and being non-White $(\mathrm{OR}=0 \cdot 9, P=0 \cdot 09)$. Money spent was not associated with any independent variables in the regression model (Table 3 ).

\section{Five dimensions of access}

Below the results are organized into overall findings of the five dimensions of access and within subheadings of each dimension: availability, accessibility, affordability, acceptability, and accommodation. Differences between older and younger

Table 1 Characteristics of participants responding to the Go Fresh mobile produce market survey, Springfield, MA, USA, October 2014: comparison of younger $v$. older adults

\begin{tabular}{|c|c|c|c|c|c|c|c|}
\hline \multirow[b]{2}{*}{ Characteristic } & \multicolumn{2}{|c|}{$\begin{array}{l}\text { All participants } \\
(N 143)\end{array}$} & \multicolumn{2}{|c|}{$\begin{array}{l}\text { Participants aged } 18-59.9 \text { years } \\
\qquad(N 82)\end{array}$} & \multicolumn{2}{|c|}{$\begin{array}{c}\text { Participants aged } \geq 60 \text { years } \\
(N 61)\end{array}$} & \multirow[b]{2}{*}{$P^{*}$} \\
\hline & $n$ & $\%$ & $n$ & $\%$ & $n$ & $\%$ & \\
\hline \multicolumn{8}{|l|}{ Sex } \\
\hline Female & 100 & $69 \cdot 9$ & 58 & $70 \cdot 7$ & 42 & 68.9 & 0.81 \\
\hline \multicolumn{8}{|l|}{ Age (years) } \\
\hline $18-59.9$ & 82 & $57 \cdot 3$ & - & - & - & - & - \\
\hline$\geq 60$ & 61 & $42 \cdot 7$ & - & - & - & - & - \\
\hline \multicolumn{8}{|l|}{ Race } \\
\hline Hispanic & 48 & $35 \cdot 8$ & 36 & $46 \cdot 2$ & 12 & $21 \cdot 4$ & 0.02 \\
\hline Black & 39 & $29 \cdot 1$ & 21 & $26 \cdot 9$ & 18 & $32 \cdot 1$ & \\
\hline White & 29 & $21 \cdot 6$ & 15 & $19 \cdot 2$ & 14 & $25 \cdot 0$ & \\
\hline Asian & 17 & $12 \cdot 7$ & 6 & $7 \cdot 7$ & 11 & $19 \cdot 6$ & \\
\hline Pacific Islander/Hawaiian & 1 & 0.8 & 0 & 0.0 & 1 & $1 \cdot 8$ & \\
\hline \multicolumn{8}{|c|}{ Residence in Go Fresh neighbourhood } \\
\hline Yes & 81 & $56 \cdot 6$ & 42 & $51 \cdot 2$ & 39 & 63.9 & 0.13 \\
\hline No & 62 & 43.4 & 40 & $48 \cdot 8$ & 22 & $36 \cdot 1$ & \\
\hline \multicolumn{8}{|l|}{ Living status } \\
\hline Alone & 45 & $32 \cdot 1$ & 14 & 17.5 & 31 & 51.7 & $<0.001$ \\
\hline With others & 95 & 67.9 & 66 & 82.5 & 29 & $48 \cdot 3$ & \\
\hline
\end{tabular}

${ }^{*} \chi^{2}$ tests were used to assess significance between younger and older adults. 
Table 2 Shopping behaviour of participants responding to the Go Fresh mobile produce market survey, Springfield, MA, USA, October 2014: comparison of younger adults $v$. older adults

\begin{tabular}{|c|c|c|c|c|c|c|c|}
\hline \multirow[b]{2}{*}{ Shopping behaviour } & \multicolumn{2}{|c|}{$\begin{array}{l}\text { All participants } \\
\qquad(N \text { 143) }\end{array}$} & \multicolumn{2}{|c|}{$\begin{array}{l}\text { Participants aged } 18-59.9 \text { years } \\
\qquad(N \text { 82) }\end{array}$} & \multicolumn{2}{|c|}{$\begin{array}{c}\text { Participants aged } \geq 60 \text { years } \\
(N 61)\end{array}$} & \multirow[b]{2}{*}{$P^{*}$} \\
\hline & $n$ & $\%$ & $n$ & $\%$ & $n$ & $\%$ & \\
\hline \multicolumn{8}{|l|}{ Primary purchaser of household } \\
\hline Yes & 117 & $86 \cdot 6$ & 69 & $87 \cdot 3$ & 48 & 85.7 & \multirow[t]{2}{*}{0.68} \\
\hline No & 18 & 13.4 & 10 & $12 \cdot 7$ & 8 & $14 \cdot 3$ & \\
\hline \multicolumn{8}{|l|}{ Number of people purchasing for } \\
\hline 1 person & 36 & $26 \cdot 7$ & 10 & $12 \cdot 7$ & 26 & 46.4 & \multirow{3}{*}{$<0.001$} \\
\hline 2-3 people & 79 & 58.5 & 52 & $65 \cdot 8$ & 27 & $48 \cdot 2$ & \\
\hline$\geq 4$ people & 20 & $14 \cdot 8$ & 17 & 21.5 & 3 & $5 \cdot 4$ & \\
\hline \multicolumn{8}{|l|}{ Frequency shopping at Go Fresh } \\
\hline Weekly & 61 & $44 \cdot 2$ & 34 & 43.6 & 27 & $45 \cdot 0$ & \multirow[t]{3}{*}{0.09} \\
\hline Once/twice per month & 40 & $29 \cdot 0$ & 18 & $23 \cdot 1$ & 22 & $36 \cdot 7$ & \\
\hline Once or twice, or first time & 37 & $26 \cdot 8$ & 26 & 33.3 & 11 & $18 \cdot 3$ & \\
\hline \multicolumn{8}{|c|}{ No. of Go Fresh locations shopped at } \\
\hline One location & 112 & $84 \cdot 2$ & 63 & 82.9 & 49 & $86 \cdot 0$ & \multirow[t]{2}{*}{0.62} \\
\hline More than one location & 21 & $15 \cdot \overline{8}$ & 13 & $17 \cdot 1$ & 8 & $14 \cdot 0$ & \\
\hline \multicolumn{8}{|l|}{ Duration shopped at Go Fresh } \\
\hline First year & 98 & $72 \cdot 1$ & 64 & $81 \cdot 0$ & 34 & $59 \cdot 6$ & \multirow[t]{3}{*}{0.002} \\
\hline Second year & 17 & $12 \cdot 5$ & 10 & $12 \cdot 7$ & 7 & $12 \cdot 3$ & \\
\hline Started $2-3$ years ago & 21 & $15 \cdot 4$ & 5 & $6 \cdot 3$ & 16 & $28 \cdot 1$ & \\
\hline \multicolumn{8}{|l|}{ Distance travelled to Go Fresh } \\
\hline Less than 1 mile $(<1.6 \mathrm{~km})$ & 96 & $72 \cdot 2$ & 58 & $74 \cdot 4$ & 38 & $69 \cdot 1$ & \multirow[t]{4}{*}{0.22} \\
\hline $1-5$ miles $(1.6-8.0 \mathrm{~km})$ & 30 & $22 \cdot 6$ & 14 & 17.9 & 16 & $29 \cdot 1$ & \\
\hline $6-10$ miles $(9.6-16.0 \mathrm{~km})$ & 4 & 3.0 & 3 & 3.8 & 1 & 1.8 & \\
\hline $11-25$ miles $(41.8-80.5 \mathrm{~km})$ & 3 & $2 \cdot 3$ & 3 & 3.8 & 0 & 0.0 & \\
\hline \multicolumn{8}{|c|}{ Amount of money spent at Go Fresh } \\
\hline <\$US 5 & 49 & $36 \cdot 6$ & 32 & $40 \cdot 5$ & 17 & 30.9 & \multirow[t]{4}{*}{0.53} \\
\hline \$US $5-10$ & 51 & 38.1 & 26 & 32.9 & 25 & 45.5 & \\
\hline \$US $11-20$ & 24 & 17.9 & 14 & $17 \cdot 7$ & 10 & $18 \cdot 2$ & \\
\hline$>\$$ US 20 & 10 & 7.5 & 7 & 8.9 & 3 & 5.5 & \\
\hline \multicolumn{8}{|l|}{ EBT use at Go Fresh } \\
\hline Yes & 40 & 29.9 & 17 & 21.5 & 23 & $41 \cdot 8$ & \multirow[t]{2}{*}{0.01} \\
\hline No & 94 & $70 \cdot 1$ & 62 & 78.5 & 32 & $58 \cdot 2$ & \\
\hline \multicolumn{8}{|c|}{ Means of finding out about Go Fresh } \\
\hline Friends & 40 & $28 \cdot 0$ & 26 & $27 \cdot 4$ & 14 & $23 \cdot 0$ & 0.25 \\
\hline Coordinator/organization & 59 & $41 \cdot 3$ & 30 & 31.6 & 29 & 47.5 & 0.19 \\
\hline News/media & 6 & 4.2 & 3 & $3 \cdot 2$ & 3 & 4.9 & 0.71 \\
\hline Workshop & 2 & 1.4 & 1 & $1 \cdot 1$ & 1 & 1.6 & 0.83 \\
\hline Flyers/postcards & 28 & $19 \cdot 6$ & 18 & 18.9 & 10 & $16 \cdot 4$ & 0.41 \\
\hline Internet/website & 4 & $2 \cdot 8$ & 3 & $3 \cdot 2$ & 1 & 1.6 & 0.47 \\
\hline Passing by & 21 & 14.7 & 14 & 14.7 & 7 & 11.5 & 0.34 \\
\hline \multicolumn{8}{|c|}{ Plans to shop at Go Fresh next year } \\
\hline Yes & 130 & 92.9 & 74 & 92.5 & 56 & 93.3 & 0.85 \\
\hline No & 0 & 0.0 & 0 & 0.0 & 0 & 0.0 & \\
\hline Don't know & 10 & 7.1 & 6 & 7.5 & 4 & $6 \cdot 7$ & \\
\hline
\end{tabular}

EBT, electronic benefit transfer.

${ }^{*} \chi^{2}$ tests were used to assess significance between younger and older adults.

†Respondents were asked to identify all that apply, so total percentages do not add up to $100 \%$.

participants for each dimension are noted under the subheadings.

Overall, location was the dimension that most participants liked about Go Fresh (72.7\%), followed by price (47.6\%), locally grown produce $(46 \cdot 2 \%)$, hours $(37 \cdot 1 \%)$, variety $(32 \cdot 2 \%)$, safety $(30 \cdot 1 \%)$ and activities, such as food demonstrations and visits by nutritionists (10.5\%). Regarding desired changes, wanting more variety was the highest response (39.5\%), followed by hours (21.1\%) and lower prices (17.7\%).

\section{Availability}

Younger participants indicated greater approval of produce variety (41.5\%) compared with older participants (19.7\%; $P=0.01$; Table 4). In response to the question, 'Are there any vegetables and fruits missing from the Go Fresh mobile market that you wish were available?', fifty-four unique food items were provided by participants. These items included twenty-seven vegetables, fifteen fruits, and two other items, bread and nuts. Hot peppers, bell or sweet peppers, cilantro (coriander), green beans, cucumbers, avocados, oranges, peaches and grapes were mentioned three to five times. Tomatoes, bananas and 'fruit' were mentioned at least six times. Fruit, unspecified and including bananas, peaches and grapes, was mentioned most often at sixteen times.

\section{Accessibility}

More than half of participants lived within one of the neighbourhoods served by MPM (56.6\%; Table 1) and 
Table 3 Logistic regression models of participant shopping behaviour at Go Fresh mobile produce market, Springfield, MA, USA, October 2014

\begin{tabular}{|c|c|c|c|c|}
\hline Dependent variable & Independent variable & OR & $95 \% \mathrm{Cl}$ & $P$ \\
\hline \multirow[t]{4}{*}{ EBT use $(n 130)$} & $\geq 60$ years old & $2 \cdot 1$ & $0.9,4.8$ & 0.09 \\
\hline & Female & 1.4 & $0.6,3.3$ & 0.46 \\
\hline & Non-White & $1 \cdot 1$ & $0.4,2.8$ & 0.89 \\
\hline & Live alone & 2.5 & $1 \cdot 1,6 \cdot 0$ & 0.03 \\
\hline \multirow[t]{5}{*}{ Spend more than $\$$ US 10 ( $n$ 125) } & $\geq 60$ years old & 1.0 & $0.4,2.5$ & 0.97 \\
\hline & Female & 0.8 & $0.3,2 \cdot 0$ & 0.67 \\
\hline & Non-White & 2.6 & $0.8,8.3$ & 0.11 \\
\hline & Live alone & 0.5 & $0.2,1 \cdot 3$ & 0.13 \\
\hline & EBT use & 1.4 & $0.5,3.5$ & 0.52 \\
\hline \multirow[t]{5}{*}{ Weekly shopping at Go Fresh ( $n$ 128) } & $\geq 60$ years old & 0.6 & $0.3,1.4$ & 0.23 \\
\hline & Female & 1.3 & $0.6,2.9$ & 0.49 \\
\hline & Non-White & 0.9 & $0.4,2.1$ & 0.79 \\
\hline & Live alone & 2.5 & $1 \cdot 1,5 \cdot 9$ & 0.03 \\
\hline & EBT use & 1.7 & $0.7,3.8$ & 0.22 \\
\hline \multirow[t]{5}{*}{ Travelled $<1$ mile $(<1.6 \mathrm{~km})$ to Go Fresh $(n 129)$} & $\geq 60$ years old & 0.6 & $0.2,1.4$ & 0.21 \\
\hline & Female & 0.8 & $0.5,2.9$ & 0.64 \\
\hline & Non-White & 0.9 & $0.1,1.2$ & 0.09 \\
\hline & Live alone & $2 \cdot 6$ & $1 \cdot 2,9 \cdot 7$ & 0.02 \\
\hline & EBT use & 1.4 & $0.5,3.7$ & 0.51 \\
\hline
\end{tabular}

EBT, electronic benefit transfer.

most were Springfield residents $(97 \cdot 7 \%)$. Almost all participants travelled $\leq 5$ miles $(\leq 8.0 \mathrm{~km})$ to the market $(94.8 \%)$, with the majority travelling $<1$ mile $(<1.6 \mathrm{~km}$; $72.2 \%$; Table 2). There was a high response to liking the market location $(72.7 \%)$, particularly among older participants $(82.0 \% ; P=0.03) ; 7.3 \%$ of younger participants wanted changes in location (Table 4 ). Nine participants wrote in comments about enjoying the convenience of location (Table 5).

\section{Affordability}

Nearly half (47.6\%) liked and $17.7 \%$ of participants wanted changes to produce price (Table 4 ). Older compared with younger participants were more likely to want changes in pricing (24.2 v. 13.4\%; $P=0.09$; Table 4). Of those who used EBT, $70 \%$ indicated satisfaction with price.

\section{Acceptability}

Nearly half of participants (46.2\%) indicated liking the produce quality of being locally grown, with there being no significant difference in perceptions between older and younger participants $(P=0 \cdot 16$; Table 4$)$. 'Other' responses to aspects liked about the market included 'freshness' (Table 4). Nine participants provided write-in comments about enjoying the produce freshness, and three more commented on the good produce quality in general (Table 5). No participants indicated dissatisfaction with the produce quality.

\section{Accommodation}

EBT was used at the MPM by about one-third of the participants $(29.9 \%)$. Older participants were more likely to use EBT (41.8\%) compared with younger $(21.5 \%$; $P=0.01$; Table 2). Two write-in comments expressed gratitude that SNAP was accepted at the MPM (Table 5).
Satisfaction with MPM hours was indicated by nearly two-fifths of participants $(37 \cdot 1 \%)$ while about one-fifth $(21 \cdot 1 \%)$ wanted a change in hours, with no significant differences in perceptions of hours between older and younger participants. 'More hours' and 'sell on Thursdays' were 'other' responses to aspects wanted changed about the market (Table 4). Four write-in comments expressed a desire for more hours (Table 5).

Safety in market location was liked by almost a third (30.1\%) of participants and was much higher than desires for changes $(2 \cdot 7 \%)$. There was no difference in perception of safety between older and younger participants (Table 4).

Participants showed an interest in the MPM offering taste sampling (44.2\%), cooking classes (23.8\%), nutritional counselling (30.6\%) and health-care information $(27.9 \%)$. Younger participants were more likely to want more activities at the MPM $(P=0.04)$ and were more interested in taste sampling $(P=0.05)$ and nutritional counselling $(P=0 \cdot 01)$ than older participants (Table 4).

Forty-five people wrote in responses to the request, 'Please share any other comments you have'. These responses captured all five dimensions of access: availability (i.e. enjoying or wanting more variety); accessibility (i.e. enjoying the convenience of the location, or not finding the location convenient, wanting additional locations); affordability (i.e. prices affordable or prices not affordable); acceptability (i.e. enjoying produce freshness and quality); and accommodation (i.e. enjoying the market setup, appreciation of EBT payment option and incentives, and desiring more hours and a winter MPM). Ten participants provided comments about the enjoyment of market staff. A quarter of the comments provided expressions of gratitude and positive experiences (Table 5). 
Table 4 Survey participants' perceptions and experiences of Go Fresh mobile produce market, Springfield, MA, USA, October 2014: comparison of younger $v$. older adults

\begin{tabular}{|c|c|c|c|c|c|c|c|}
\hline \multirow[b]{2}{*}{ Question } & \multicolumn{2}{|c|}{$\begin{array}{l}\text { All participants } \\
(N 143)\end{array}$} & \multicolumn{2}{|c|}{$\begin{array}{l}\text { Participants aged 18-59.9 years } \\
\text { (N 82) }\end{array}$} & \multicolumn{2}{|c|}{$\begin{array}{c}\text { Participants aged } \geq 60 \text { years } \\
(N 61)\end{array}$} & \multirow[b]{2}{*}{$P$} \\
\hline & $n$ & $\%$ & $n$ & $\%$ & $n$ & $\%$ & \\
\hline \multicolumn{8}{|l|}{ Aspects liked ${ }^{*}$} \\
\hline Variety & 46 & $32 \cdot 2$ & 34 & 41.5 & 12 & 19.7 & 0.01 \\
\hline Location & 104 & $72 \cdot 7$ & 54 & 65.9 & 50 & $82 \cdot 0$ & 0.03 \\
\hline $\begin{array}{l}\text { Price } \\
\text { Pas }\end{array}$ & 68 & $47 \cdot 6$ & 41 & 50.0 & 27 & $44 \cdot 3$ & 0.50 \\
\hline Locally grown & 66 & $46 \cdot 2$ & 42 & $51 \cdot 2$ & 24 & $39 \cdot 3$ & 0.16 \\
\hline Safety & 43 & $30 \cdot 1$ & 24 & $29 \cdot 3$ & 19 & $31 \cdot 1$ & 0.81 \\
\hline Hours & 53 & $37 \cdot 1$ & 28 & 34.1 & 25 & 41.0 & 0.40 \\
\hline Activities $†$ & 14 & 10.5 & 8 & $9 \cdot 8$ & 6 & $9 \cdot 8$ & 0.99 \\
\hline Write-in responses & 2 & 1.4 & 2 & 2.4 & 0 & 0.0 & \\
\hline \multicolumn{8}{|l|}{ Aspects wanted changed* } \\
\hline More variety & 57 & 39.5 & 33 & $40 \cdot 2$ & 24 & $38 \cdot 7$ & 0.91 \\
\hline Location & 6 & 4.8 & 6 & 7.3 & 0 & 0.0 & 0.04 \\
\hline Pricing & 26 & $17 \cdot 7$ & 11 & 13.4 & 15 & 24.2 & 0.09 \\
\hline Safety & 4 & 2.7 & 2 & 2.4 & 2 & 3.2 & 0.76 \\
\hline Hours & 30 & $21 \cdot 1$ & 18 & $22 \cdot 0$ & 12 & 21.0 & 0.74 \\
\hline More activities & 6 & $4 \cdot 1$ & 6 & $7 \cdot 3$ & 0 & 0.0 & 0.04 \\
\hline Nothing & 30 & $21 \cdot 1$ & 16 & 19.5 & 14 & $22 \cdot 6$ & 0.62 \\
\hline Write-in responses & 5 & 3.4 & 2 & 2.4 & 3 & 4.8 & \\
\hline \multicolumn{8}{|l|}{ Future activities desired* } \\
\hline Taste sampling & 65 & $44 \cdot 2$ & 43 & 52.4 & 22 & 35.5 & 0.05 \\
\hline Cooking classes & 34 & 23.8 & 23 & 28.0 & 11 & $19 \cdot 4$ & 0.16 \\
\hline Nutritional counselling & 44 & $30 \cdot 6$ & 32 & 39.0 & 12 & 21.0 & 0.01 \\
\hline SNAP or health-care info & 40 & 27.9 & 20 & $24 \cdot 4$ & 20 & $32 \cdot 3$ & 0.27 \\
\hline None/not interested & 17 & $12 \cdot 2$ & 7 & 8.5 & 10 & $16 \cdot 1$ & 0.15 \\
\hline Write-in responses & 2 & 1.4 & 0 & 0.0 & 2 & 3.2 & \\
\hline
\end{tabular}

SNAP, Supplemental Nutrition Assistance Program; WIC, Special Supplemental Nutrition Program for Women, Infants, and Children.

${ }^{\star}$ Respondents were asked to identify all that apply, so total percentages do not add up to $100 \%$.

†Current activities included food demonstrations and visits by WIC nutritionists.

\section{Discussion}

Our findings suggest that MPM influence access to healthful food choices within deficient food environments and that older and younger adults appear to have differing perceptions on some dimensions of access. Ours is the first study to apply the five dimensions of access framework to capture a market intervention influence on access to fruits and vegetables. We applied the framework to the perceptions of consumers in an urban environment with residents living within food deserts. The MPM captured all dimensions of access.

Go Fresh adds a source of produce to neighbourhoods, influencing availability, defined as the supply of food and presence of stores ${ }^{(10)}$. Our data showed mixed perceptions of the variety of produce offered, with a greater satisfaction in variety among younger compared with older adults. Overall study participants indicated a desire for more of the items that Go Fresh offered (such as cilantro and tomatoes), cultural varieties such as recao (a long-leafed variety of cilantro), and items that are not grown locally such as bananas, oranges and avocados. This might reflect cultural preferences given that Hispanic/ Latinos comprised a significant proportion of our participants. Particular preferences for ethnic options among African Americans and Latinos ${ }^{(46)}$ as well as limited availability of culturally specific fruits and vegetables in many neighbourhoods ${ }^{(47)}$ have been highlighted as important considerations for improving the food environment to meet the needs of residents. The desire for MPM to include staple food items such as bread and milk for onestop shopping was expressed in another MPM study ${ }^{(31)}$. While only two participants in our study indicated a desire for non-produce items, our results suggest that sourcing more produce, particularly fruit, and culturally specific produce such as recao, may satisfy and draw additional customers. Taste sampling may also improve shopper satisfaction with the current variety of produce because it might offer shoppers the opportunity to taste unfamiliar fruits and vegetables ${ }^{(31)}$.

Accessibility of MPM locations and close proximity to residences was highlighted as an important reason for shopping at Go Fresh. Our findings that most MPM shoppers were Springfield residents, lived within one of the neighbourhoods served by MPM, travelled less than 1 mile $(1.6 \mathrm{~km})$ to market and liked the market locations underscore the mobility of MPM as an important asset to this marketing system and support the intention that MPM improve local access to produce for people living in food deserts $^{(31,32,48,49)}$, addressing food deficits and diet-related health issues related to living in food deserts ${ }^{(50)}$. Despite the intention of MPM to improve accessibility to fruits and vegetables by making the location more convenient and by serving areas lacking fresh produce options, studies on 
Table 5 Responses to open-ended survey question 'Please share any additional comments', categorized into the five dimensions of access, among participants responding to the question $(n 45)$ in the Go Fresh mobile produce market survey, Springfield, MA, USA, October 2014

\begin{tabular}{|c|c|c|}
\hline $\begin{array}{l}\text { Dimension of } \\
\text { access }^{*}\end{array}$ & Comment type & Frequency \\
\hline \multirow[t]{2}{*}{ Availability } & Want more variety $\dagger$ & 2 \\
\hline & Enjoy variety & 1 \\
\hline \multirow[t]{3}{*}{ Accessibility } & Enjoy convenience $†$ & 9 \\
\hline & Not convenient† & 1 \\
\hline & Want more locationst & 1 \\
\hline \multirow[t]{2}{*}{ Affordability } & Affordable & 1 \\
\hline & Not affordable† & 1 \\
\hline \multirow[t]{3}{*}{ Acceptability } & Enjoy freshness $†$ & 9 \\
\hline & Enjoy quality & 3 \\
\hline & 'Prefer organic' & 1 \\
\hline \multirow[t]{4}{*}{ Accommodation } & Enjoy market 'set up' & 1 \\
\hline & Grateful that SNAP is accepted & 2 \\
\hline & Want more hourst & 4 \\
\hline & Want winter market & 1 \\
\hline \multirow[t]{3}{*}{$\begin{array}{l}\text { Other } \\
\text { comments }\end{array}$} & $\begin{array}{l}\text { Positive experiences/expressions of } \\
\text { gratitude }\end{array}$ & 14 \\
\hline & $\begin{array}{l}\text { Enjoy staff - 'excellent' 'friendly' } \\
\text { 'nice' 'professional', 'pleasant' }\end{array}$ & 10 \\
\hline & $\begin{array}{l}\text { Request to keep Facebook page } \\
\text { updated }\end{array}$ & 1 \\
\hline
\end{tabular}

SNAP, Supplemental Nutrition Assistance Program.

*Each participant's response may have multiple comments that fit into more than one category.

†Write-in response overlaps with discrete response categories from other questions.

Green Carts, a special permitted MPM in New York City, have found some MPM vending locations straying from areas with limited access and clustered around areas with greater commercial activity, sometimes competing with other stores selling fruits and vegetables ${ }^{(19,33)}$. These findings are contrary to the current study. Go Fresh maintained its route throughout the duration of the 2014 season. In subsequent years, Go Fresh locations were modified to better serve vulnerable populations such as increasing the number of affordable housing sites and locations that were frequented by older adults. One reason for the difference may be that Go Fresh is a non-profit that is subsidized by grants and business sponsorship, while the Green Carts are for-profit businesses and therefore may gravitate to areas of higher sales. Similar to our findings, the need for more MPM locations ${ }^{(31)}$ and transportation options to $\mathrm{MPM}^{(51)}$ have been expressed in previous MPM research.

The importance of affordability as an impetus for shopping at Go Fresh, indicated by produce price being the second most favoured characteristic of Go Fresh, supports findings from studies in New York that surveyed Green Cart customers ${ }^{(32)}$ and older adult shoppers of the Veggie Mobile ${ }^{(26)}$ that found affordable prices to encourage shopping at MPM. Go Fresh aims to offer produce at prices that reflect current grocery store prices so there is no price differential, and to incentivize produce purchases through $50 \%$ discounts for all EBT users. An MPM study in Syracuse, NY demonstrated affordability by showing that seven of nine items offered by the MPM were lower than grocery store prices ${ }^{(52)}$. Our data suggest that EBT use and accompanying incentives facilitate affordability among low-income participants. Although only a third of participants used EBT, close to three-quarters of those who used EBT at Go Fresh indicated satisfaction with produce price. Our study extends the research showing SNAP benefits as an important facilitator for purchasing fresh fruits and vegetables among people with low incomes ${ }^{(53)}$ into another, perhaps more accessible market, the MPM. The importance of leveraging food assistance programmes to increase MPM use was identified in an MPM study in which $40 \%$ of their participants expressed lack of affordability as a barrier to MPM use, particularly at the end of the month when people ran out of money or SNAP benefits $^{(31)}$. Our data suggest that SNAP and accompanying discount for EBT users were important for facilitating affordability particularly among older adults and those who lived alone. Our data also reflect contradicting experiences of affordability, with some participants identifying the need to improve pricing. Improvements in perceived affordability might be achieved by providing more information on SNAP benefits, which was desired by over a quarter of participants, and by posting comparison prices from supermarkets.

Study participants' appreciation of produce quality being fresh and locally grown demonstrates acceptability of the MPM as a source of fruits and vegetables and supports other research findings that low-income customers of farmers' market and MPM have enjoyed the fresh quality of produce $(26,28,53)$

While we did not set out to measure the quality of the relationship between customers and market staff as an indicator of acceptability ${ }^{(13,44)}$, the importance of social interactions and relationships emerged from our data. Ten participants wrote in comments about positive experiences with market staff, suggesting that social interactions positively influenced shopper experience. Social networks were also important for initiating MPM use, with the highest two responses of finding out about Go Fresh being through coordinator/organizations and friends. In a study using focus groups to interview shoppers and nonshoppers of four MPM in different parts of the country, the theme of trust emerged, and participants expressed the importance of building trusting relationships with market staff and the preference for staff being from their own community $^{(31)}$. MPM acceptability may be improved through intentionality around community building, which was an important objective of the Community Development Corporation Mobile Market in Syracuse, NY that has become a vital social space particularly for older adults ${ }^{(52)}$. The importance of social relationships between consumers and food providers has been discussed in literature on local food systems through the conceptualization of social embeddedness ${ }^{(54,55)}$ and should be examined in greater depth as a factor influencing food access in food 
environment research. Considering that perceptions of staff were the most often unsolicited comment from our participants, future research could benefit from examining the quality of social relationships as a factor influencing food access and an indicator of acceptability.

Perceived safety of MPM locations was one indicator of accommodation. Crime and other issues with safety in neighbourhoods can discourage people from walking to nearby food outlets ${ }^{(56,57)}$. A study that examined food access disparities in New York City found that when crime and poor traffic safety were considered in food environments, disparities in access to a supermarket widened and negatively impacted food access in the poorest neighbourhoods and neighbourhoods with higher proportions of Black, Hispanic and Asian residents ${ }^{(56)}$. By travelling directly to residential sites such as apartment buildings and to community centres where consumers may be comfortable, MPM can mitigate safety issues that may otherwise be of concern. While neighbourhood safety has not been explicitly defined as an indicator of accommodation in previous five dimensions of access frameworks ${ }^{(10,13,44)}$, future applications of the framework should consider its inclusion.

Perceptions of market hours, another indication of accommodation, was mixed in our study. While over a third of our study participants liked the market hours, almost a quarter wanted changes in hours. Unlike supermarkets that are open most days and evenings, MPM usually are open for short periods of time (1-2h) at each location that may not accommodate individual schedules ${ }^{(31,58)}$. Hours for each of Go Fresh's market stops in 2014 were on weekdays, lasting from 1 to $1 \frac{1}{2} \mathrm{~h}$, between $10 \mathrm{am}$ and $5 \mathrm{pm}$. Interviews from a study of Fresh to You, an MPM in Rhode Island, found that working adults had a difficult time attending market due to work conflicts ${ }^{(58)}$. In subsequent years, Go Fresh increased the hours of operation by adding weekend hours in an effort to accommodate more people.

Having a higher EBT use rate among older participants may indicate Go Fresh's capacity to accommodate lowincome older adults despite potential stigma with SNAP participation that is often magnified in older adults ${ }^{(51,59)}$. National rates of SNAP participation in 2014 show SNAP enrolment by only $42 \%$ of eligible older adults ( $\geq 60$ years) compared with $85 \%$ of eligible adults aged $<60$ years ${ }^{(60)}$. A study examining EBT use at Green Carts in the Bronx, NY found that EBT users spent an average of \$US 3.81 more per transaction compared with those who paid by cash, suggesting that EBT use may support increased fruit and vegetable purchases and subsequently increased fruit and vegetable consumption ${ }^{(61)}$.

Our data suggest that Go Fresh accommodated the needs of those living alone, which is promising in the light of findings of greater nutritional risk among those living alone $^{(1,62)}$. Living alone was associated with EBT use, shopping weekly and travelling $<1$ mile $(<1.6 \mathrm{~km})$. Those living alone may benefit from the opportunity for social interaction offered by $\mathrm{MPM}^{(28)}$, which could partly explain their weekly commitment to shopping at Go Fresh. Research shows that gathering places like community centres and congregate meals are important for breaking social isolation and lowering the risk of malnutrition, particularly among older adults living alone ${ }^{(63)}$.

Older adults, who are more likely to face challenges to food access due to transportation, mobility and health limitations ${ }^{(64)}$, may particularly benefit from MPM, which can bring healthful foods closer to home. Lack of transportation is a commonly perceived barrier to fruit and vegetable access among older adults ${ }^{(64,65)}$ and older adults in urban areas rely on walking/walkable neighbourhoods and public transportation to acquire groceries ${ }^{(36,66)}$. In our study, older participants had a higher response to liking the market location, suggesting accessibility as an important MPM facilitator of produce access particularly for older adults. Similarly, in an intervention study examining the introduction of the Veggie Mobile to two senior housing sites in Troy, NY, convenience of MPM location was identified as the most-liked aspect of the MPM by $77 \cdot 8 \%$ of older adult shoppers ${ }^{(26)}$. Our findings that older participants had a longer shopping history at Go Fresh and shopped at the MPM more frequently compared with younger participants may indicate greater accommodation among older adults, who may need to shop more frequently in small batches to avoid spoilage and the burden of carrying large groceries ${ }^{(36)}$. A qualitative study that used interviews and observations to examine shopping behaviours of older adults in Brooklyn, NY found that older adults typically shopped at least once per week, bought a few items at a time, and often shopped at multiple stores to acquire food that met their desire for quality, fit their budgets, and where they trusted the business practices ${ }^{(36)}$. Although our study did not find significant differences in perceptions and experiences of quality or price between older and younger participants, older adults' appreciation and preference for fresh, nonprocessed, healthful, high-quality food at a low cost has been consistent in the literature on older adult shopping behaviours ${ }^{(36,67,68)}$. Being on a fixed budget with added medical expenses underscores the importance of low-cost food for many older adults ${ }^{(1,69)}$, but may be less pronounced (i.e. different from younger adults) when considered in the context of a low-income population in which the need for affordability is commonplace. Our finding that fewer older adults responded to liking the produce variety compared with younger adults may be related to older adults' preferences for starchy vegetables $^{(1)}$, habitually consumed ${ }^{(67,70)}$ and culturally specific produce varieties $^{(36)}$, and staple food items ${ }^{(31)}$ not offered at the MPM.

Overall, our study found that MPM captured the five dimensions of access to fruits and vegetables. Previous research has shown that fruit and vegetable purchases ${ }^{(27)}$ and consumption increased ${ }^{(26-28)}$ in MPM intervention 
sites and that shoppers consumed more fruits and vegetables than non-shoppers ${ }^{(31)}$. Our study sets the foundation for examining how MPM fit into the broader food environment nationally and internationally. Our findings may be used to better understand drivers of access to previous research that has shown MPM being used as a primary ${ }^{(28)}$ and supplementary ${ }^{(48)}$ source of fruits and vegetables. In developing countries and US urban centres where street food and other mobile vendors sell a variety of foods including prepared foods, mobile market users may face different challenges to healthful food access, such as food safety or competition with unhealthful foods ${ }^{(25,71)}$. In these settings, the five dimensions of access framework may be applied to better understand the nuances of these markets' influence on healthful food access.

\section{Strengths and limitations}

The current study had several strengths. We had a high response rate: 147 of 180 shoppers (81.6\%) participated in the study. Translating the questionnaire into Spanish and Vietnamese enabled the inclusion of customers with different language preferences. The questionnaire had closed-ended and open-ended questions; many closedended questions had an 'other' category that allowed participants to provide additional information. For two dimensions, both objective and subjective indicators of access were included to enhance analysis of the five dimensions of access, such as the objective measure of distance travelled to MPM as well as perceptions of the MPM locations.

There are several potential limitations to the current study. Our findings capture the perceptions and experiences of shoppers at one urban MPM and therefore may not reflect rural areas or other MPM that may have operational differences. The use of a convenience sample did not include non-shoppers or former shoppers who may have had poor experiences with the MPM. This may have increased positive perceptions of the MPM and may have missed important aspects of access. However, our findings included both satisfaction and dissatisfaction for four dimensions of access, found differences in perceptions between older and younger adults, and demonstrated that each dimension was able to be captured in a food environment intervention. This convenience sample allowed us to identify aspects of dimensions that will help refine the application of the five dimensions of access to the food environment. For example, inclusion of interactions between shoppers and market staff may facilitate understanding of the acceptability dimension and inclusion of neighbourhood safety may do the same for accommodation. Another potential limitation is the use of 'locally grown' as a proxy indicator of quality. Although superior freshness and taste are commonly perceived quality indicators attributed to locally grown food ${ }^{(68)}$, our study participants may have interpreted 'locally grown' in different ways. In a review of consumers' perceptions and preferences for local food, perceived attributes of local food included supporting the local economy, environmentally friendly growing practices and greater food safety ${ }^{(68)}$. Among a sample of older Australians (>60 years) in a qualitative study, greater healthfulness and food safety were attributed to locally produced food ${ }^{(67)}$. Future studies may want to explore other measures of food quality and attributes of 'locally grown', such as direct questions on the quality of produce, or food safety, that may influence consumers' perceived acceptability of produce, and to be more specific with the language and indicators used for quality. In addition, a checklist of characteristics that demonstrate produce quality could be added as an objective measure of acceptability.

While findings from the current study demonstrated variability between dimensions of access, our research design did not allow us to set a criterion or threshold to demonstrate changes in or facilitation of access. Food environment interventions may benefit from research that uses mathematical models applied to larger populations to set thresholds to indicate facilitation of access for each dimension.

\section{Conclusion}

We used a novel approach to assess an MPM intervention through five dimensions of access, demonstrating the framework's applicability for researchers and public health organizations to assess food access, and expanding understanding of how MPM facilitate access to fruits and vegetables. We look beyond conventional measures of access that tend to focus on healthy food availability within a food outlet or geographic boundary, instead broadening access to consider the combinations of more indicators, including: perceptions of produce variety, price and quality; perceptions of market location, hours and safety; distance travelled to market and EBT use. By examining nuances of MPM influence on fruit and vegetable access, we examine the complexity of food access, involving social, cultural, economic and structural factors that influence individuals' interactions with their food environment. Our study sets the foundation for evaluating an intervention through multiple dimensions of access. Future studies should continue to refine measures used to capture multiple dimensions, for example develop indicators to reflect an intervention/food environment's accommodation of cultural food preferences. More studies capturing the five dimensions of access are needed to establish thresholds within each dimension for evaluating interventions.

The present study suggests that MPM may influence fruit and vegetable access in low-income urban neighbourhoods with limited fruit and vegetable access and may especially benefit older adults and individuals living alone. Our finding that living alone was associated with three shopping behaviours (i.e. EBT use, shopping at Go Fresh 
weekly, travelling $<1$ mile $(<1.6 \mathrm{~km})$ to Go Fresh) sets the foundation for future research about food acquisition behaviour related to living alone or household status, and the economic and social importance of food environment interventions. The role of social interactions in facilitating better nutrition and health outcomes is lacking in current MPM literature and would provide valuable insight on the impact of MPM.

\section{Acknowledgements}

Acknowledgements: The authors thank the study participants for their valuable contribution to this study. Financial support: This work was supported by the US Department of Agriculture, National Institute of Food and Agriculture, Multistate NC1196 and Hatch MAS00465 (grant number \#1002626). The opinions expressed in this article are the authors' own and do not reflect the view of funders. Conflict of interest: All authors declare no conflicts of interest. Authorship: B.H. conceptualized the study, led data analysis and interpretation, and wrote the manuscript. L.S. assisted in conceptualizing the study. K.W. contributed to the development of the survey instrument and led the data collection. L.M.T. oversaw the study, assisted in conceptualizing the study, contributed to data interpretation, and assisted in writing the manuscript. All authors contributed to revising the manuscript and approved the final version. Ethics of buman subject participation: This study was conducted according to the guidelines laid down in the Declaration of Helsinki and all procedures involving human subjects were approved by The Institutional Review Board at University of Massachusetts Amherst. Verbal informed consent was obtained from all subjects. Verbal consent was witnessed and formally recorded.

\section{References}

1. Nicklett EJ \& Kadell AR (2013) Fruit and vegetable intake among older adults: a scoping review. Maturitas $\mathbf{7 5}$, 305-312.

2. Boeing H, Bechthold A, Bub A et al. (2012) Critical review: vegetables and fruit in the prevention of chronic diseases. Eur J Nutr 51, 637-663.

3. Moore L \& Thompson F (2015) Adults Meeting Fruit and Vegetable Intake Recommendations - United States, 2013. http://www.cdc.gov/mmwr/preview/mmwrhtml/mm6426a1. htm (accessed June 2016).

4. Gustafson A, Hankins S \& Jilcott S (2012) Measures of the consumer food store environment: a systematic review of the evidence 2000-2011. J Community Health 37, 897-911.

5. Morland K, Wing S \& Roux A (2002) The contextual effect of the local food environment on residents' diets: the atherosclerosis risk in communities study. Am J Public Health 92 , 1761-1767.

6. Fraser LK, Edwards KL, Cade J et al. (2010) The geography of fast food outlets: a review. Int J Environ Res Public Health 7, 2290-2308.

7. Larson NI, Story MT \& Nelson MC (2009) Neighborhood environments disparities in access to healthy foods in the US. Am J Prev Med 36, 74-81.
8. Hilmers A, Hilmers DC \& Dave J (2012) Neighborhood disparities in access to healthy foods and their effects on environmental justice. Am J Public Health 102, 1644-1654.

9. Black C, Moon G \& Baird J (2014) Dietary inequalities: what is the evidence for the effect of the neighbourhood food environment? Health Place 27, 229-242.

10. Caspi CE, Sorensen G, Subramanian SV et al. (2012) The local food environment and diet: a systematic review. Health Place 18, 1172-1187.

11. Chen X \& Kwan MP (2015) Contextual uncertainties, human mobility, and perceived food environment: the uncertain geographic context problem in food access research. Am J Public Health 105, 1734-1737.

12. Kelly B, Flood VM \& Yeatman H (2011) Measuring local food environments: an overview of available methods and measures. Health Place 17, 1284-1293.

13. Penchansky R \& Thomas J (1981) The concept of access definition and relationship to consumer satisfaction. Med Care 19, 127-140.

14. Flint E, Cummins S \& Matthews S (2013) Do perceptions of the neighbourhood food environment predict fruit and vegetable intake in low-income neighbourhoods? Health Place 24, 11-15.

15. Andress L \& Fitch C (2016) Juggling the five dimensions of food access: perceptions of rural low income residents. Appetite 105, 151-155.

16. Sharkey JR, Dean WR \& Johnson CM (2012) Use of vendedores (mobile food vendors), pulgas (flea markets), and vecinos o amigos (neighbors or friends) as alternative sources of food for purchase among Mexican-origin households in Texas border colonias. J Acad Nutr Diet 112, 705-710.

17. Valdez Z, Dean WR \& Sharkey JR (2012) Mobile and homebased vendors' contributions to the retail food environment in rural South Texas Mexican-origin settlements. Appetite 59, 212-217.

18. Rosales R (2013) Survival, economic mobility and community among Los Angeles fruit vendors. J Ethn Migr Stud 39, 697-717.

19. Lucan SC, Maroko A, Shanker R et al. (2011) Green Carts (mobile produce vendors) in the Bronx - optimally positioned to meet neighborhood fruit-and-vegetable needs? J Urban Health 88, 977-981.

20. Glanz K, Sallis JF, Saelens BE et al. (2007) Nutrition Environment Measures Survey in Stores (NEMS-S): development and evaluation. Am J Prev Med 32, 282-289.

21. Moustier P, Loc NTT, Son HT et al. (2008) Promotion of public-private dialogue to maintain poor-friendly fruit and vegetable street vending in Hanoi. In Proceedings of the Second International Symposium on Improving the Performance of Supply Chains in the Transitional Economies, Hanoi, Vietnam, September 23-27, 2007, pp. 239-246 [PJ Batt, editor]. Louvain: ISHS.

22. Steyn NP \& Labadarios D (2011) Street foods and fast foods: how much do South Africans of different ethnic groups consume? Ethn Dis 21, 462-466.

23. Webb RE \& Hyatt SA (1988) Haitian street foods and their nutritional contribution to dietary-intake. Ecol Food Nutr 21, 199-209.

24. Drabo KT, Savadogo LG, Tarnagda Z et al. (2009) Main characteristics of the street food sector in Bobo-Dioulasso, Burkina Faso. Bull Soc Pathol Exot 102, 36-40.

25. Steyn NP, Mchiza Z, Hill J et al. (2014) Nutritional contribution of street foods to the diet of people in developing countries: a systematic review. Public Health Nutr 17, 1363-1374.

26. AbuSabha R, Namjoshi D \& Klein A (2011) Increasing access and affordability of produce improves perceived consumption of vegetables in low-income seniors. J Am Diet Assoc 111, 1549-1555. 
27. Evans AE, Jennings R, Smiley AW et al. (2012) Introduction of farm stands in low-income communities increases fruit and vegetable among community residents. Health Place 18, 1137-1143.

28. Jennings A, Cassidy A, Winters T et al. (2012) Positive effect of a targeted intervention to improve access and availability of fruit and vegetables in an area of deprivation. Health Place 18, 1074-1078.

29. Tester JM, Yen IH \& Laraia B (2012) Using mobile fruit vendors to increase access to fresh fruit and vegetables for schoolchildren. Prev Chronic Dis 9, 110222.

30. Tester JM, Stevens SA, Yen IH et al. (2010) An analysis of public health policy and legal issues relevant to mobile food vending. Am J Public Health 100, 2038-2046.

31. Zepeda L, Reznickova A \& Lohr L (2014) Overcoming challenges to effectiveness of mobile markets in US food deserts. Appetite 79, 58-67.

32. Fuchs E, Holloway S, Bayer K et al. (2014) Innovative Partnership for Public Health: An Evaluation of the New York City Green Cart Initiative to Expand Access to Healthy Produce in Low-income Neighborboods. vol. 2: Case 2. New York: Columbia University School of International and Public Affairs.

33. Li KY, Cromley EK, Fox AM et al. (2014) Evaluation of the placement of mobile fruit and vegetable vendors to alleviate food deserts in New York City. Prev Chronic Dis 11, E158.

34. Centers for Disease Control and Prevention (2015) Healthy Aging: Helping Older Americans Achieve Healthy and HighQuality Lives. At A Glance 2015. http://www.cdc.gov/ chronicdisease/resources/publications/aag/healthy-aging.htm (accessed June 2016).

35. Keller H \& McKenzie J (2003) Nutritional risk in vulnerable community-living seniors. Can J Diet Pract Res 64, 195-201.

36. Munoz-Plaza CE, Morland KB, Pierre JA et al. (2013) Navigating the urban food environment: challenges and resilience of community-dwelling older adults. I Nutr Educ Behav 45, 322-331.

37. US Census Bureau (2017) State and County Quick Facts. http://www.census.gov/quickfacts/table/PST045216/00 (accessed February 2017).

38. Statistical Atlas (2015) Race and ethnicity in Springfield, Massachusetts. Figure: neighborhood/non-white-population. http://www.statisticalatlas.com/place/Massachusetts/ Springfield/Race-and-Ethnicity (accessed July 2017).

39. Statistical Atlas (2015) Age and sex in Springfield, Massachusetts. Definitions. http://www.statisticalatlas.com/place/ Massachusetts/Springfield/Age-and-Sex (accessed August 2017)

40. Pioneer Valley Planning Commission (2014) Data Atlas by Neighborbood for the City of Springfield, MA. Springfield, MA: Pioneer Valley Planning Commission.

41. US Department of Agriculture, Economic Research Service (2017) Food Access Research Atlas. http://www.ers.usda. gov/data-products/food-access-research-atlas/about-theatlas/ (accessed March 2017).

42. Caspi CE, Kawachi I, Subramanian SV et al. (2012) The relationship between diet and perceived and objective access to supermarkets among low-income housing residents. Soc Sci Med 75, 1254-1262.

43. Caldwell EM, Kobayashi MM, DuBow WM et al. (2009) Perceived access to fruits and vegetables associated with increased consumption. Public Health Nutr 12, 1743-1750.

44. Usher KM (2015) Valuing all knowledges through an expanded definition of access. J Agric Food Syst Community Dev 5, 109-114.

45. Martinez SH, Da Pra M, Pollack S et al. (2010) Local Food Systems: Concepts, Impacts, and Issues, Economic Research Report no. ERR-97. Washington, DC: US Department of Agriculture, Economic Research Service.

46. Fish CA, Brown JR \& Quandt SA (2015) African American and Latino low income families' food shopping behaviors: promoting fruit and vegetable consumption and use of alternative healthy food options. J Immigr Minor Health 17, 498-505.

47. Grigsby-Toussaint DS, Zenk SN, Odoms-Young A et al. (2010) Availability of commonly consumed and culturally specific fruits and vegetables in African-American and Latino neighborhoods. I Am Diet Assoc 110, 746-752.

48. Marina S, Blum J \& Bettisworth C (2014) Closing the Winter Gap: An Evaluation of Somerville Winter Mobile Farmers' Market. http://as.tufts.edu/uep/sites/all/themes/ asbase/assets/documents/fieldProjectReports/2014/Team6 GroundworkSomerville.pdf (accessed February 2016).

49. Widener MJ, Metcalf SS \& Bar-Yam Y (2012) Developing a mobile produce distribution system for low-income urban residents in food deserts. J Urban Health 89, $733-745$.

50. US Department of Agriculture, Economic Research Service (2009) Access to affordable and nutritious food: measuring and understanding food deserts and their consequences. Report to Congress. https://www.ers.usda.gov/webdocs/ publications/42711/12716_ap036_1_.pdf?v=41055 (accessed March 2017).

51. Haynes-Maslow L, Auvergne L, Mark B et al. (2015) Lowincome individuals' perceptions about fruit and vegetable access programs: a qualitative study. J Nutr Educ Behav $\mathbf{4 7}$, 317-347.

52. Robinson JA, Weissman E, Adair S et al. (2016) An oasis in the desert? The benefits and constraints of mobile markets operating in Syracuse, New York food deserts. Agric Hum Values 33, 877-893.

53. Karakus M, MacAllum K, Milfort R et al. (2014) Nutrition Assistance in Farmers Markets: Understanding the Shopping Patterns of SNAP Participants. http://www.fns.usda.gov/ sites/default/files/FarmersMarkets-Shopping-Patterns.pdf (accessed February 2016).

54. Sage C (2003) Social embeddedness and relations of regard: alternative 'good food' networks in south-west Ireland. I Rural Stud 19, 47-60.

55. Hinrichs CC (2000) Embeddedness and local food systems: notes on two types of direct agricultural market. I Rural Stud 16, 295-303.

56. Bader MDM, Purciel M, Yousefzadeh P et al. (2010) Disparities in neighborhood food environments: implications of measurement strategies. Econ Geogr 86, 409-430.

57. Odoms-Young AM, Zenk S \& Mason M (2009) Measuring food availability and access in African-American communities: Implications for intervention and policy. Am J Prev Med 36, 4 Suppl. 1, 145-150.

58. Gorham G, Dulin-Keita A, Risica PM et al. (2015) Effectiveness of fresh to You, a discount fresh fruit and vegetable market in low income neighborhoods, on children's fruit and vegetable consumption, Rhode Island, 2010-2011. Prev Chronic Dis 12, E176.

59. Gabor V, Williams S, Bellamy H et al. (2002) Seniors' Views of the Food Stamp Program and Ways to Improve Participation - Focus Group Findings in Washington State. Final Report no. EFAN-02-012. Washington, DC: US Department of Agriculture, Economic Research Service.

60. Gray KF \& Cunnyngham K (2016) Trends in Supplemental Nutrition Assistance Program Participation Rates: Fiscal Year 2010 to Fiscal Year 2014. Washington, DC: US Department of Agriculture, Food and Nutrition Service.

61. Breck A, Kiszko KM, Abrams C et al. (2015) Spending at mobile fruit and vegetable carts and using SNAP benefits to pay, Bronx, New York, 2013 and 2014. Prev Chronic Dis 12, E87.

62. Deierlein AL, Morland KB, Scanlin K et al. (2014) Diet quality of urban older adults age 60 to 99 years: the Cardiovascular Health of Seniors and Built Environment Study. J Acad Nutr Diet 114, 279-287. 
63. Walker D \& Beuchene R (1991) The relationship of loneliness, social-isolation, and physical health to dietary adequacy of independently living elderly. J Am Diet Assoc 91, 300-304.

64. Wolfe WS, Frongillo EA \& Valois P (2003) Understanding the experience of food insecurity by elders suggests ways to improve its measurement. J Nutr $\mathbf{1 3 3}$, 2762-2769.

65. Haynes-Maslow L, Parsons SE, Wheeler SB et al. (2013) A qualitative study of perceived barriers to fruit and vegetable consumption among low-income populations, North Carolina, 2011. Prev Chronic Dis 10, E34.

66. Chung WT, Gallo WT, Giunta N et al. (2012) Linking neighborhood characteristics to food insecurity in older adults: the role of perceived safety, social cohesion, and walkability. J Urban Health 89, 407-418.
67. Pettigrew S, Worrall C, Biagioni N et al. (2017) The role of food shopping in later life. Appetite 111, 71-78.

68. Feldmann C \& Hamm U (2015) Consumers, perceptions and preferences for local food: a review. Food Qual Prefer $\mathbf{4 0}$, $152-164$.

69. Wolfe WS, Olson CM, Kendall A et al. (1996) Understanding food insecurity in the elderly: a conceptual framework. J Nutr Educ 28, 92-100.

70. Pettigrew S \& Moschis G (2012) Consumer well-being in later life. In Transformative Consumer Research for Personal and Collective Well-Being, pp. 565-581 [DG Mick, S Pettigrew, C Pechmann et al., editors]. New York: Taylor \& Francis.

71. Lucan SC, Maroko AR, Bumol J et al. (2014) Mobile food vendors in urban neighborhoods - implications for diet and diet-related health by weather and season. Health Place 27, $171-175$. 